This paper was accepted on $4^{\text {th }}$ November 2016

The paper will be published in early 2017 under the following:

Begum, L., and Anjum, M (2017), Beyond the Creative Class, Mapping the Collaborative Economy of Bangladeshi Creative Industries: Case Study of Oitij-jo, South Asian Popular Culture, Special Issue on South Asian Creative Industries (eds), Dudrah, R., and Malik, K.

http://explore.tandfonline.com/cfp/ah/rsap-call-for-papers-south-asian-creative-and-culturalindustries

This paper is subject to final publisher changes 


\section{Beyond the creative class, mapping the collaborative economy of Bangladeshi creative industries: case study of Oitij-jo}

\section{Lipi Begum}

Winchester School of Art, University of Southampton, Winchester, United Kingdom

Winchester Centre for Global Futures in Art, Design and Media, Park Avenue, Winchester SO23 8DL, United Kingdom, 1.begum@soton.ac.uk

Dr Lipi Begum is lecturer and programme leader for the MA in Fashion Management at the Winchester School of Art, University of Southampton. She is co-editor of the book Styling South Asian Youth Cultures and Fashion, IB Tauris (2017) and is Reviews Editor for the International Journal of Fashion Studies (Intellect). Lipi has worked as a consultant for the United Nations Better Work in Textiles and Garments project in Dhaka, Bangladesh and is part of the Oitij-jo FDTC (Fashion, Design and Textiles Collective) strategic advisory team.

\section{Maher Anjum}

Anjum-James Associates, London, United Kingdom

maheranjum1@googlemail.com

Maher Anjum believes in connecting all the dots to provide sustainable long-term solutions that look after people, planet and profits. Maher has successfully managed across various sectors including the creative industries. She has facilitated networks for B2B innovation, design and research. She is the co-founder of Oitij-jo. 


\section{Beyond the creative class, mapping the collaborative economy of Bangladeshi creative industries: case study of Oitij-jo}

This paper documents how the British Bangladeshi diaspora in the UK has been collaborating to contribute to the growth of the creative sector in the UK and in Bangladesh. Through case studies from the creative-start-up of Oitij-jo (February 2013) and subsequently the planning of its second project 'AKHON: Where is Bengal Now', this paper charts the collaborations between the culture and creative industries of Bengali heritage (film, photography, theatre, dance, music, art, architecture, textiles \& fashion) involved in the project between 2013-2016. The authors question widely used policy notions of 'the creative class' and 'creative clustering' and explore the collaborative economy model for the growth of Bangladeshi cultural and creative industries.

Using infographics and netnographic interviews, the paper maps out advantages and disadvantages of collaboration linked to digital and non-digital peer-to-peer skills sharing and entrepreneurship. It concludes with the next steps for Oitij-jo and discusses the managerial implications for sustainability of its future projects.

Keywords: creative industries, Bangladesh, heritage, collaborative economy, Oitij-jo 


\section{Bangladeshis in Creative Britain}

The UK's creative sector is one of the most consistently successful sectors in the country. It is estimated ${ }^{1}$ that between 2008 and 2012 the UK creative sector contributed $£ 71$ billion to the economy, representing an increase of $15.6 \%$ compared to the overall economy which grew by $5.6 \%$ (DCMS 2014). Given the sector's growth and future growth potential in fashion, digital industries, software development, architecture and performance arts, this paper explores how the British Bangladeshi diaspora in the UK have been collaborating with their counterparts in Bangladesh and globally to innovate, be motivated and contribute to the growth of the creative sector in the UK and in Bangladesh.

British Bangladeshi's have been travelling and settling in Britain since the $18^{\text {th }}$ and $19^{\text {th }}$ Century as lascars (sailors) and ayahs (Visram 1986). Post World War II, men arrived along with their compatriots from other commonwealth countries to cities across the UK to run services and rebuild them (Visram 2002). It was not until the birth of Bangladesh and the change in UK immigration rules of the 'right of entry' in 1971, that Bangladeshi men increasingly settled in the UK and started to bring their families over (Sommerville et al 2009). In particular, the 1980s saw a surge of the Bangladeshi community settling from Bangladesh to the UK (Li 2015) and since then Bangladeshi's have been integrating into the UK community through education and work.

${ }^{1}$ Figures on the creative industries are based on what the DCMS 2016 report classifies as experimental estimates of the value of the Creative Economy. These figures are not absolute and are what the Code of Practice for Official Statistics defines as Experimental Official Statistics, undergoing evaluation and review each year. For further details on methodology, see the methodology section of the full report 
In accordance to the $2011^{2}$ Census, $0.8 \%$ of UK's population or 447,000 people in the UK are of British Bangladeshi origin. Degree level qualification among the 16-24 year old age group is proportionally higher than any of the other age groups (Lymperopoulou 2014). It is estimated the percentage of 'no qualification' saw a significant drop between 2001 and 2011 from $47 \%$ to $28 \%$, a difference of $19 \%$ within a decade. In 2011 the overall attainment difference between the genders also decreased (men 24\% and women 33\%) and among the 16-24 year old age group there is virtually no difference (Lymperopoulou 2015). In fact, in 2014 the number of British Bangladeshi youngsters achieving five good GCSEs was higher (61\%) than Pakistani (51\%) or indigenous White British populations (54\%) (Li 2015).

In spite of the advances made in education for the British Bangladeshi population of UK, majority of them still live in low-income social housing concentrated in London (Alzubaidi et al 2013). Although the distribution of income has risen for those of Bangladeshi households than previously (Li 2015) the levels of economic activity amongst the British Bangladeshi community remain slow. According to the 2011 Census, men of Bangladeshi origin were $53 \%$ likely to be working in low-skilled jobs and $67 \%$ for women. $54 \%$ of men in employment worked in part-time jobs and less than thirty hours per week and $12 \%$ worked in jobs that were less than fifteen hours a week. For women the figures are just as striking, 56\% and $23 \%$ respectively (ONS 2014).

Overall, British Bangladeshi's have come a long way since the 1980s. The anecdotal evidence is that South Asian communities have a preference for professions in law, medicine, accountancy or education. The creative sectors are not seen as a real form of employment or source of income (Evans 2009). Yet a new generation of settled British Bangladeshis are breaking into non-traditional creative sectors and are increasingly becoming renowned for their creativity. For example winner of The BBC Great British Bake Off (2015), Nadiya

\footnotetext{
${ }^{2}$ It was not possible to include up-to-date statistics on the Bangladeshi community with regards to education and the creative industries, as there was limited data available on the topic. Where possible, estimates are provided and statistics are treated as quality measures to be built upon by stakeholders, refer to previous footnote.
} 
Hussain and Akram Khan MBE the dancer are two particular instances here. The participation of Bangladeshis within the creative economy of the UK is under-recognised. Creative practices of theatre, dance, drama, poetry, textile and crafts that have a long tradition in Bangladesh and Bengal are not known, understood, or are reflective of the lives of the community in the UK. Additionally, Bangladesh is the second largest garments and apparel exporter globally (Saxena 2014), however this achievement of the garments sector is tainted by recent tragic factory incidences of Tazreen and Rana Plaza. It can be said that the creative sector is one of the fastest growing sectors in the UK, yet has had very little impact on the British Bangladeshi diaspora community.

It is within this backdrop and vacuum of creative Bangladeshi/Bengali ${ }^{3}$ imagery that we set the discussion for the rest of the paper. In this paper, through the case study of Oitij-jo, a notfor-profit platform, we showcase creativity motivated by the creative heritage of Bangladeshi and Bengali origin. Oitij-jo illustrates how contrary to the negativity of a low-skilled, low innovation image, Bangladeshi and Bengali heritage is historically and currently rich in creativity and high in skills. We discuss how a lack of cultural understanding of what often constitutes a worthwhile creative investment in the Bangladeshi community by policy makers and funders, hinders the growth of Bangladeshi creative industries. We explore the cultural relevance of policy notions, such as creative class (Florida 2002) and creative clustering (De Propis and Hyponnen 2008) and the benefits of going beyond these approaches towards collaborative economy models (Stokes et al 2014), which support greater skills management and growth of the British Bangladeshi creative industries and its practitioners.

\footnotetext{
${ }^{3}$ We use Bengali and Bangladeshi interchangeably in this paper. Bengali refers to the historical identity of Bangladesh when it belonged to the region of Bengal in India, and when the region shared its identity across west Bengal and East Bengal (which later became East Pakistan after partition during the Indian Independence movement) before Indian independence/partition in 1947. In this paper, we mostly choose to use the term Bangladeshi to reinforce and to de-stigmatise the Bangladeshi cultural identity, which has been overshadowed by Indo-Pak relations since Bangladesh's independence from Pakistan in 1971. Yet we recognise and appreciate that Bangladesh's cultural identity is inextricably linked to Bengali heritage post-partition and shared across west Bengal in India and Bangladesh, therefore we use these terms interchangeably.
} 


\section{Methodology}

Oitij-jo (www.oitijjo.org) was founded in October 2012 by architect Ruhul Abdin (male, age 25-40) and independent consultant Maher Anjum (female, age 41-60). Ruhul's interests are in urban development in emerging countries and Maher came from working in the creative industries of London and Bangladesh. Oitij-jo in Bangla means heritage, however the naming reflects a dynamic rather than static and stagnant past. It can be summarised as a heritage that is learning from and looking at the past for the present, to better develop and deliver in the future. Oitij-jo started out with the vision to present creative excellence and achievement of Bengali traditions in the arts and crafts, to enrich and enhance the present perception of Bengali arts and crafts and to ensure prosperity of lively arts and crafts practices (Oitij-jo 2015).

Oitij-jo's initial steering committee in 2012 included Independent British Bangladeshi photographer Enamul Hoque (male, age 41-60) and Abbas Nokahsteh (male, age 41-60) founder of Openvizor (www.openvizor.com an international non-profit arts and cultural organisation currently working in over fifteen countries). Other members of the committee included Runi Khan (female, age 61-80) of CulturePot Global a performing arts company (https://www.facebook.com/CulturepotGlobal/) and John Baker (male, age 61-80) a voluntary sectors worker with over fifty years experience working for the borough of Tower Hamlets in East London. For Oitij-jo 2013, support was also received from the then High Commissioner of Bangladesh to the UK, Quayes Mohamed Mijarul. The Oitij-jo collective went on to register as a not-for profit company in October 2013; with Ruhul, Maher, Abbas and Enamul being registered as founding directors later in 2015.

In this chapter through the start-up journey of Oitij-jo UK, we illustrate a series of anecdotal case studies and infographics to demonstrate how open platforms like Oitij-jo can enhance a wealth of networks necessary for nurturing entrepreneurship and growth. This is irrespective of whether creatives fit into the classification of popular policy approaches such as 'the creative class' (Florida 2002). The case illustrates the challenges and barriers of creative 
collaboration, concluding with ways forward for the growth and planning of Oitij-jo's second project $A K H O N /$ Where is Bengal NOW.

The information was gathered from the inaugural Oitij-jo event that took place in February 2013 and the feedback that followed in 2011 and in 2015. It also includes the feedback from the most recent event in March 2016 to launch the planned 2017/ 2018 festival. We applied a netnographic (Kozinets 2015) approach to data collection. We conducted qualitative online interviews with artists and planners behind the Oitij-jo event and culturally contextualised online information on Oitij-jo from its Facebook page, Twitter account, official website and gathered online interviews. We also documented projects related to Bangladeshi heritage that have taken place as a result of volunteer networking and conversations at the Oitij-jo events. In keeping with the netnographic philosophy, the information is visually contextualised using infographics to illustrate the possibilities of creative collaboration and to make data accessible to a wider audience.

\section{A Cultural Perspective on Creative Class and Creative Clustering}

Firstly, it is important for us to understand what the role and impact of creative industries is to the UK's economy and as a nation. It is estimated that the number of jobs in the creative industries (including both creative and support jobs) increased by 5.5 per cent between 2013 and 2014 to 1.8 million jobs. Total employment in the creative economy across the UK increased by 5.0 per cent between 2013 and 2014 (2.6 million to 2.8 million jobs), compared with a 2.1 per cent increase in the total number of jobs in the wider UK economy over the same period (DCMS 2016).

Over the last decade, this growth has been reflected in policy dialogues and debates taking place in the UK and increasingly across the globe. This global shift is charted in the move away from the term cultural industries to creative industries (Evans 2009). Culture and 
cultural industries are no longer instruments of the nation-state, confined to broadcasting, arts and heritage but global creative industries. In 2004 UNCTAD (United Nations Conference on Trade and Development) said that creative industries were the crossroads between the arts, business and technology (DCMS 2014). This re-definition is also a reflection of the discussion by proponents of the 'creative city' e.g. work of Florida (2002) and other creative city advocates (Landry 2000; Nichols Clark 2004). These advocates believed that a 'tolerant', 'open' and vibrant place attracts creative and knowledge workers (Evans 2009) and what Florida terms the 'creative class'. In essence it is this notion of the creative class that started the discussion on creative industries and creative sectors.

If we take a step back, Florida (2002) argues that highly educated creative professionals such as architects, artists and non-fiction writers are catalysts to city development. Florida argues that the three drivers of creative class are technology, talent and tolerance (3Ts) and that cities which achieve these 3Ts attract high-tech investment and growth. However, Florida's approach did not take into account regional development, or the diversity of the communities who share and compete for creative spaces within the city. A community within a city may receive investment on the basis of Florida's 3Ts, however this overlooks other creative communities in the same city who lack visibility within mainstream creative education, socio-economic mobility and ultimately equal access to technology, talent and tolerance.

This dominant notion of the 'creative class' as an answer to the sustainable competitiveness of a city has been challenged by those who have looked at unevenly distributed cultural industries, the wide range of industries that constitute cultural industries and the differences within them (e.g. fashion, film, music, TV, games, advertising). However many policy dialogues still follow the hegemonised debate of the creative class. Pratt (2009) calls this the normative policy debate or the 'Xerox' policy. It is salient in Florida's work that policy needs to take into account the uniqueness of a context, however Pratt (2009) argues popularisation of the work of Florida's $3 \mathrm{~T}$ is an example of how diversity is still to be understood. These 
normative policy dialogues are typically seen in most widely used policy initiatives, such as the creative cluster model (De Propis and Hyponnen 2008).

According to De Propris \& Hyponnen (2008) a creative cluster is a place that brings together a community of 'creative people' who share an interest in novelty but not necessarily in the same subject: a catalysing place where people, relationships, ideas and talents can spark each other; an environment that offers diversity, stimuli and freedom of expression; a thick, open and ever-changing network of inter-personal exchanges that nurture individual's uniqueness and identity. The advantages of creative clustering include creative spillovers that lead to future collaborations and innovations, regional and transnational economic development, increase in demand and co-location opportunities via networks close to each other, or social media.

Creative clustering poses as a solution to its lesser creative and scientific roots of strategic clustering (Porter 1980) ${ }^{4}$, however it still operates within a scientific framework that favours a science policy to culture and creative industries (Pratt 2009). The use of creative clustering is widely used in cultural policymaking and has now been adopted by economically driven industries such as real estate, science, sport and I.T (Mommaas 2009; Pratt 2009). Mommaas (2009) argues that the term has given rise to an appealing agenda but at the same time hides 'a confusing and tense complexity' (Mommaas 2009). Mommaas argues that creative

\footnotetext{
${ }^{4}$ Clustering is a strategic management approach popularised by management scholar Michael Porter. Porter defined clusters as geographical concentrations of interconnected companies and institutions within a particular field, an array of linked industries and other entities important to competition (Porter 1990). Porter argues that if countries are to remain competitive; related industries need to stay geographically close together. The reasons being, nations are likely to increase competitiveness if specialized skills and industries are clustered together to drive greater levels of competition, innovation and growth between them.
} 
clustering notions are not made explicit and the histories of creative clustering strategies are diverse and complex.

It is not to say that we cannot learn from the notion of the creative class (2002) and creative clustering (De Propis and Hyponnen 2008). For instance digital co-location advantages of creative clustering can be combined with geographic spillover and silo-breaking advantages of Porter's strategy-orientated clustering approach. For cultural creative industries that are emergent, diverse and starting from an unequal footing (in terms of investment and access to growth) policy notions such as the collaborative economy (Stokes et al 2014) are better suited.

Collaborative economy definitions are varied and are constantly evolving, however the main idea around the collaborative economy, or the peer-to-peer/sharing economy is the idea of access (Stokes et al 2014) compared to the ownership approach of the three 3Ts. 'Collaborative economies encourage decentralised networks over centralised institutions, and unlock wealth (with and without money). They make use of idle assets and create new marketplaces. In doing so, many also challenge traditional ways of doing business, rules, and regulations' (Stokes et al 2014: 7). Examples of this approach are brands like Air BnB, Ebay and Massive Online Courses (MOOCs). The ideas which make up a collaborative economy are not new and overlap and extend policy notions such as creative class, creative clustering and south Asian cultural approaches to frugal innovation like Jugaad (Radjou et al 2012). However, the emphasis placed upon a decentralised and open approach makes it an attractive policy approach for those looking to overcome socio-political and economic barriers to public funding, and those seeking to build informal networks via better and quicker access to technology and skills and ideas exchange at little cost.

The following section through the illustrative infographics and online interviews demonstrates how collaborative economy models are useful for overcoming social and economic barriers to reaching out to creatives within disparate markets. The case contextualises the limitation of popular creative industry policy approaches, such as creative 
clustering and creative class approach for the British Bangladeshi creative and cultural industries.

\section{Visualising Oitij-jo 'Past Present Future'}

'Past, Present, Future' was the title for the first event in 2013. The event engaged with over seventy artists of the Bengali diaspora and was received well (see www.oitijjo.org). The first event took place at the Bargehouse, South Bank, London in February 2013. The following infographic visualises the Oitij-jo landscape.

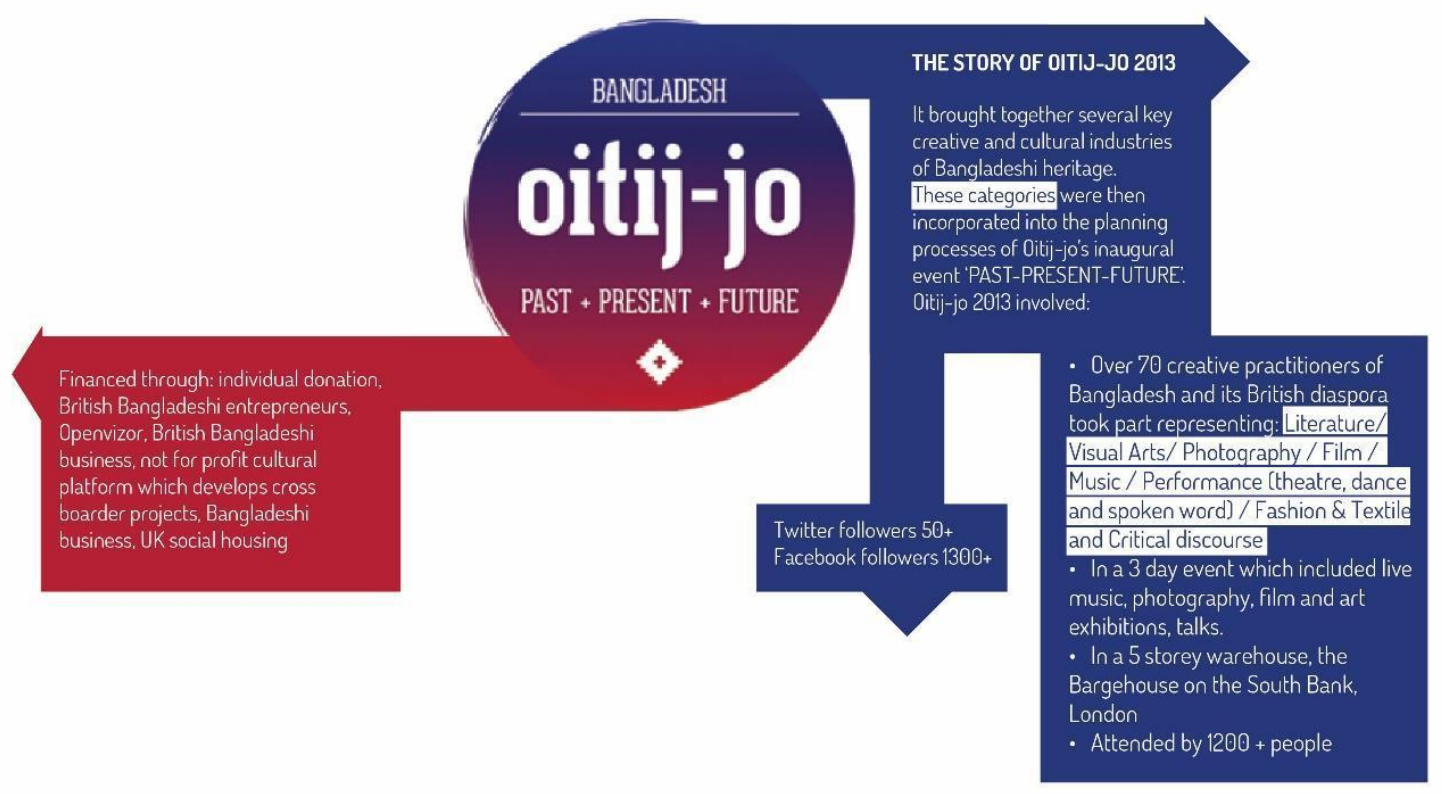

Infographic 1: The Story of Oitij-jo 2013, created by Nòemi Zajzon $\subset$ 
As seen in infographic one, Oitij-jo mapped out the key cultural industries of Bangladesh and incorporated them into the planning processes of Oitij-jo's inaugural event 'Past-PresentFuture' in 2013. This event was held over three days and was attended by over 1500 people. The infographic above illustrates how the event, financed mostly by independent charities and British Bangladeshi entrepreneurs, brought together key cultural industries of Bangladeshi heritage including: literature, visual arts, photography, fashion \& textiles, film and art. These practices were supported through the open platforms of interactive displays, performances, talks, debates and exhibitions.

The first event relied on volunteers participating on a pro-bono basis. Volunteers came from all backgrounds, ages and experiences to put the event together. The manner in which the event was planned worked well for some volunteers, however it was conflicting with others. We found that, success factors were also barriers and were predominantly related to the challenges surrounding informal and decentralised peer-to-peer skills sharing, entrepreneurship and leadership approaches. The following section maps out and further explains this dialectical process of learning. 


\section{digital and non-digital skills sharing oitij-jo map}

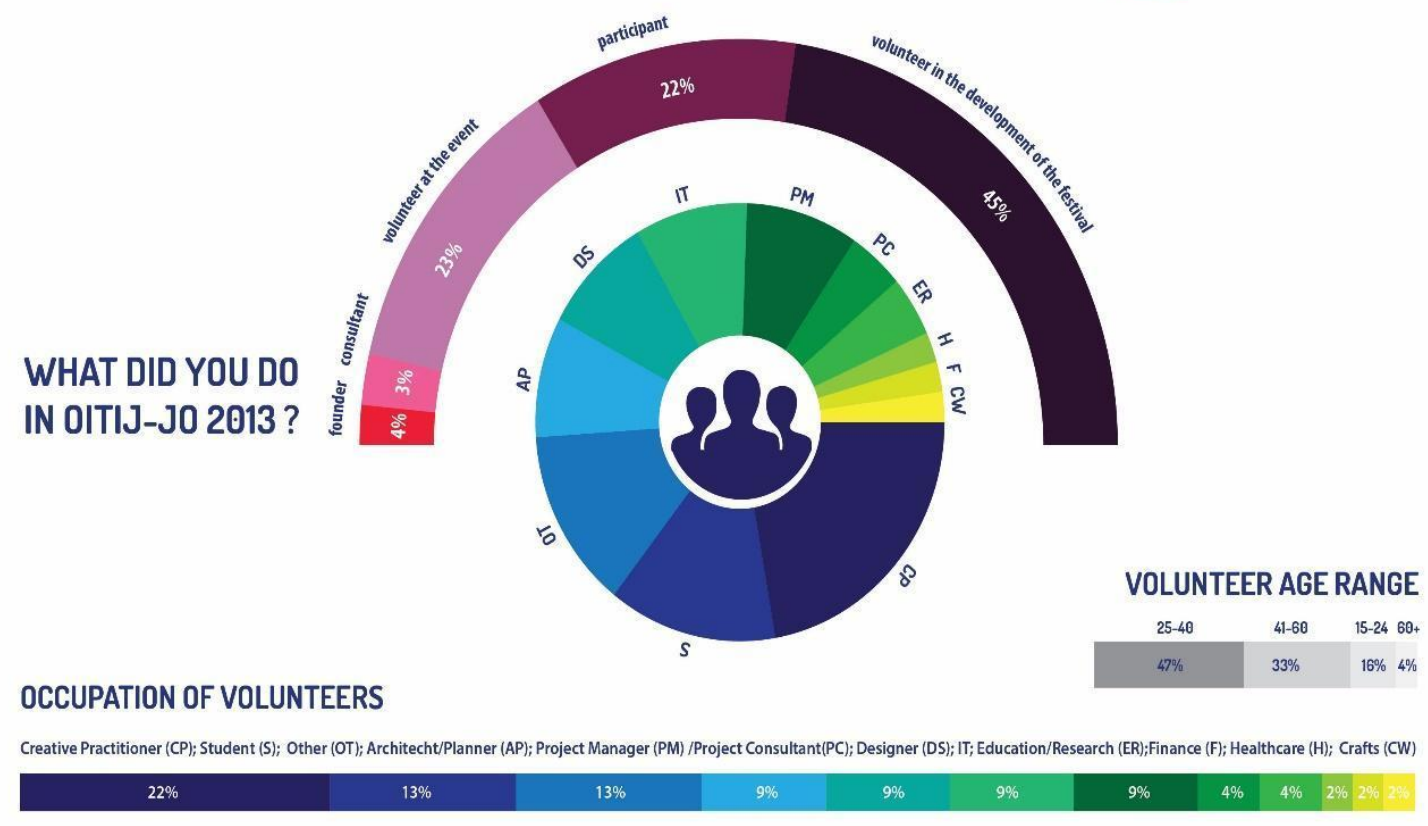

Infographic 2: Digital and Non-digital Skills Sharing Map, created by Nòemi Zajzon`

Oitij-jo's first event was an open and collaborative platform. Infographic two essentially illustrates the key role volunteers played in this process. This decentralised and open approach was undertaken to cut the costs of organising an event with access to limited funding, a short space of time in Central London and within a large venue. As illustrated in infographic two, volunteers can be categorised as follows: volunteers from a practicing creative background; volunteers from a non-creative background but interested in the creative sector; professionals who were keen to build new networks; students both creative and noncreative. Infographic two depicts how voluntary collaborations between over seventy artists 
and non-artists, across platforms took place during the planning of the event, and in as little as six months.

To be specific, creatives in this context included those who were directly working as creative practitioners such as musicians, dancers, filmmakers, photographers, writers and curators. Non-creatives in this context included those working outside of the creative sectors, example those working in banking, law, healthcare, catering, logistics, I.T, Management among others. What infographic two illustrates is how Oitij-jo created a space for networking, collaborating and skills sharing across digital (social media and email) and non-digital (faceto-face during events and planning meetings) platforms between those already engaged and new to the creative sector (in this context creatives and non-creatives). The volunteers, creatives and non-creatives also came through to Oitij-jo through their collaboration with other networks like BritBangla, Brick Lane Circle, Swadhinata Trust, British Bangladeshi Fashion Council, Emerald Network and a long list of individuals.

One of the benefits from the volunteering process for many was being able to informally exchange and learn creative skills. During an online interview a non-Bangladeshi art student from Malta, expressed the opinion that getting involved in Oitij-jo was 'a way to get involved in the local art scene whilst undertaking his masters in Culture Criticism and Curation in London' (male, age 41-60). Another non-Bangladeshi textile artist who regularly works on arts projects within her Bangladeshi neighbourhood in East-London, said during an interview 'I found it an accessible platform to connect with others doing similar projects' (female, age 41-60). Here the non-Bangladeshi artist and the art student are examples of how creative practitioners gained greater awareness and understanding of creative practices related to Bangladeshi heritage through volunteering at Oitij-jo.

Other advantages of peer-to-peer skills sharing included new and established artists gaining confidence from the professional and social relationships formed over what was an intense period of planning. One emerging fashion designer (female, age 25-40,) explained during an online interview how 'being involved with the members of Oitij-jo really helped to be more 
confident in talking to potential clients and like-minded people and expressing myself and my work'. For other artists, it provided them with the confidence to nurture existing ideas and 'learn more about events management (female, age 25-40, online interview)' and the 'business and planning side of things' (male, 25-40, online interview), and importantly skills sharing between creative practitioners and volunteers beyond the Oitij-jo event. This is seen within the timeline illustrated in infographic three. 


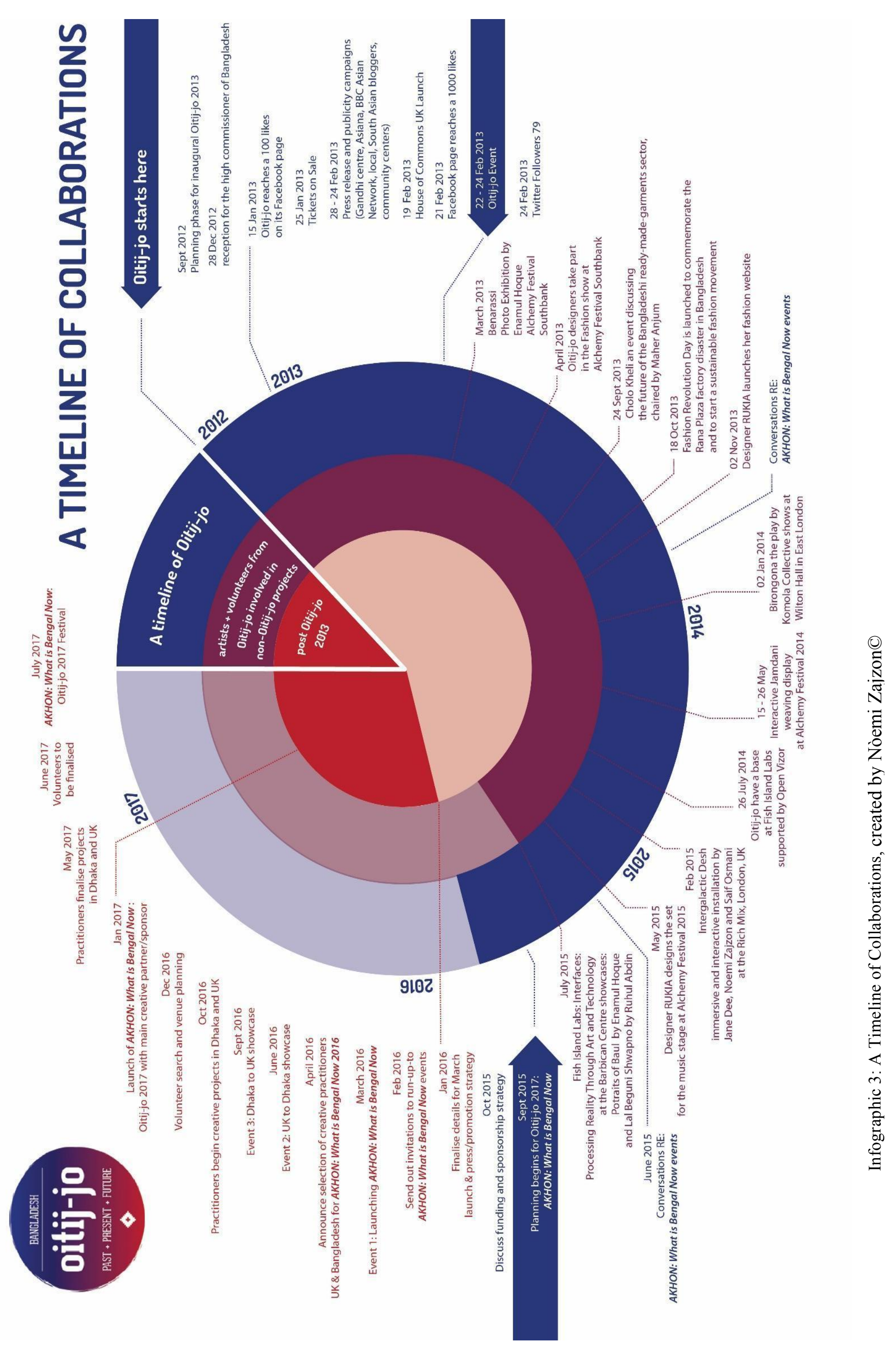


Infographic three maps the parallel and ongoing creative dialogues sparked between artists and volunteers throughout the event planning process and after the event. These dialogues took place between the period 2012 and 2015 and are ongoing as part of the planning process for the next Oitij-jo festival in 2017/ 2018.

Infographic three illustrates the rich, intertwining and complex post-Oitij-jo 2013 collaborations. These collaborations took place as a result of creative practitioners and volunteers directly and indirectly working with and engaging with those they met through Oitij-jo 2013. For some it wasn't easy to separate how they were motivated or which connections they made before or after the Oitij-jo event, however their participation in Oitijjo became a motivator to remain engaged with the Bangladeshi cultural and creative industries. One of the co-founders (male 25-40) explained over Gmail chat how

'It was interesting to see other collaborations emerge from the festival especially connections between Enamul Hoque [male, age 41-60, photographer] and Leesa Gazi [female, 41-60 theatre and TV producer] and some of the young volunteers now working very closely with artists, one volunteer [female, age 16-24, Business Management undergraduate student] is working for the big dancer Akram Khan. The projects we have been developing in collaboration (such as the street kid's film) with Openvizor and The Rainbow Collective has been fascinating. Another development I feel was a great output, was the ability to network with other artists and support each other'

Skills sharing and entrepreneurial endeavours were not always driven by the need for artistic expression alone and were also borne out of a sense of individual desire to enter into competitive creative industries and make projects work within time and resource constraints and limited management direction. One volunteer in an interview stated 'I felt left out, there was no time to attend to me, but I believed in the cause so kept going' (female, age 25-40). Another British-Bangladeshi community artist describes how 'Bangladeshi's are naturally entrepreneurial but time constraints are de-motivating for those looking to experience what it is like to work in a creative career' (male, age 25-40). These entrepreneurial endeavours were 
also catalysed by the hallmark of collaborative economy activities i.e. the Internet and social media (Botsman and Rogers 2010), which enabled an intricate network of connections to occur within a short period of time - this is illustrated in infographic four.

\section{NETWORKS}

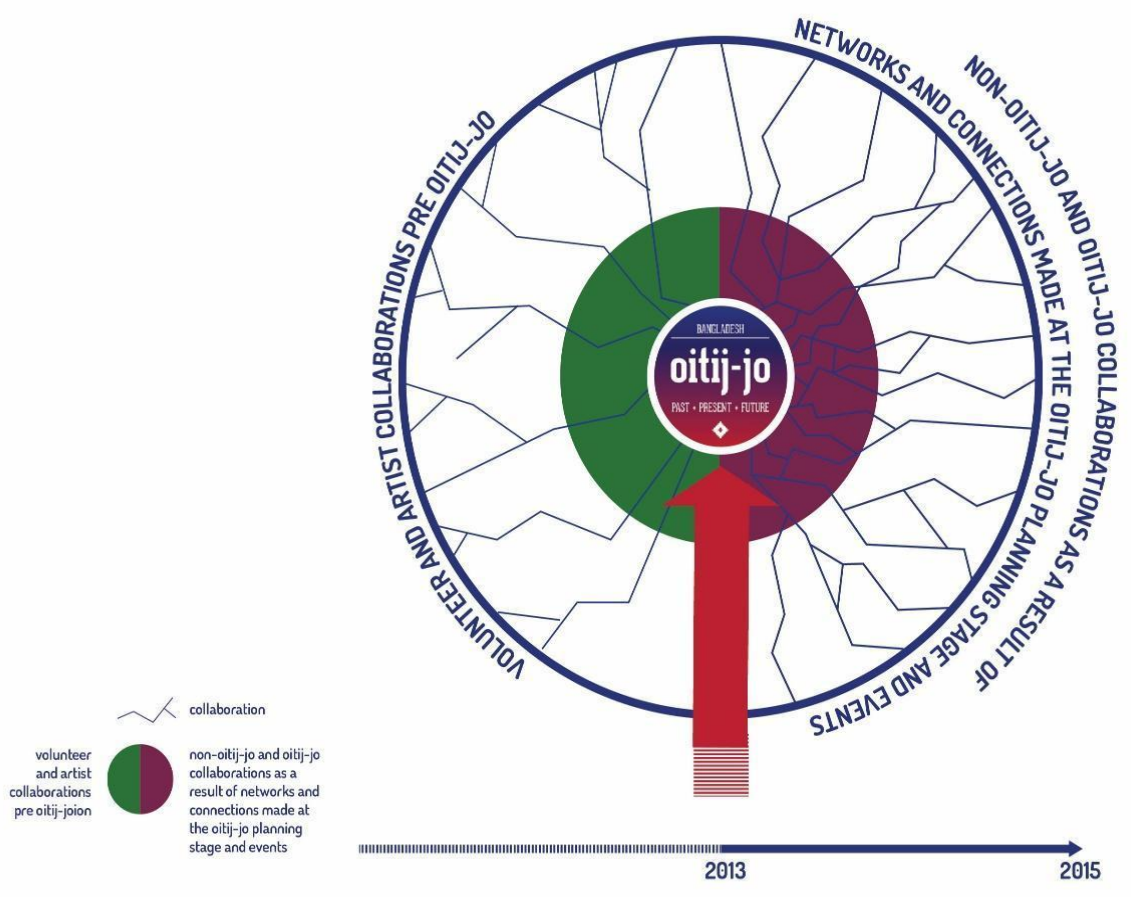

Infographic 4: Networks, created by Nòemi Zajzon®

The established nature of the London arts and creative industries scene meant the geographic location of London was an attractive advantage for creatives to connect. However it was the co-location advantages of social media and word-of-mouth simultaneously, which played a bigger role in the crowdsourcing of volunteers who did not always frequent the established arts London scene and were looking for accessible work experience in the creative industries. The use of technology to source creatives and volunteers for the event proved successful. Through emails, social media (LinkedIn, Facebook and Twitter) and personal websites. The volunteers in the organising team were able to draw together three artists in film, five in 
fashion, fourteen in theatre and music, two in dance, four in photography, six in creative education, two in art, five in literature, four in sustainable fashion and textile including twenty volunteers interested in the arts who assisted in the development of the event.

The Oitij-jo Facebook page was an accessible and low-cost marketing tool. It was able to reach the volunteers and over a thousand followers within four months. (https://www.facebook.com/oitijjolondon/). Facebook helped communicate a message of openness, inclusivity and open-access and common sharing of images and text (Botsman and Rogers 2010; Stokes et al 2014) between volunteers and artists - all of which are necessary for collaborative economy activities to flourish. For some artists the publicity received from the Oitij-jo event was more important than the consumption of their work through ticket sales. Those who could not come to the events, engaged with the cultural and creative industries of Bangladesh through accessible interactions through Facebook likes, follows, LinkedIn connections and Tweets. According to one of the social media managers for events (male, age 25-40), 'Facebook was a great public relations tool to spread the Oitij-jo message quickly and reach out to wider and younger Bangladeshi and non-Bangladeshi audience'. Social media allowed artists to consume other artist's work and come together to engage with new cultural ideas. 
The interaction over social media blurred those who were consuming arts and those producing the art. Ownership became access. This is seen where those with limited experience of the creative industries were introduced to Bangladeshi cultural and creative industries through Oitij-jo. One non-Bangladeshi cultural ambassador (male, age 60+) in the community states:

'I have developed an appreciation of the work of the Rainbow Collective and Komola Collective, and now consider myself a working friend of both... Through all these contacts and friends I've been 'introduced' to the world of Bengali music, especially to the work of Khiyo and Lokhi Terra. Numerous websites and Facebook pages account the activities of the groups I've mentioned, and a couple of short texts credited to me have appeared in 'The Geographical Magazine', photography by Enamul'

Aside from generating awareness and inviting the community to engage, technology was also a logistical tool for setting up ticket selling platforms and managing sales. The usage of an Eventbrite platform facilitated the sale of tickets for the three-day event and allowed participants and guests from across the globe to learn about the programme and access their tickets. According to one of the organisers (male, age 25-40) during an interview:

'Facebook was definitely a big tool used to promote and engage with the festival attendants, and twitter was also relatively useful. Communication streams internally and externally were managed through the Internet, as well as using the website to promote events at the festival. It was where people could purchase tickets. The relative ease of the tools such as Facebook and website with a content management system, meant we could keep costs down and do a lot of the marketing and promoting ourselves'

\section{Next Steps: Beyond Borders}

Based on the lessons learnt from volunteers and organisers from the first event, planning is seen as a priority. The next series of events will be hosted across an eighteen-month period as a build-up to the final event to allow planning to happen in incremental steps (can be seen in infographic three). This period would also be utilised for raising funds and creating events to 
build and attract a wider audience and reach for the next festival planned for $2017 / 2018$. Volunteer feedback from the first event included the need to create internship opportunities for volunteers in the creative sectors, as well as, project dissemination strategies that incorporate schools, colleges and community centres in local and regional areas. It was also observed that engagement is necessary from the wider artistic community and a greater number of artists. Therefore a key consideration in moving forward is to develop artist residencies to build material for the next festival, which would also require further financial backing.

In order to reach out to the wider creative community, the steering committee decided to focus on expanding the term Bangladeshi to Bengali heritage. The first event captured both Bengali and Bangladeshi heritage, however many felt this didn't come across and the term Bengali was more inclusive and sustainable for the long-term future of Oitij-jo. As a result of this change, and various planning meetings and conversations, the second London Oitij-jo festival theme was agreed as 'AKHON: Where is Bengal Now?

AKHON: Where is Bengal Now centres on the importance of the creative industry as a critical tool for transformation towards a cohesive and engaged society. The theme for the festival is rooted in visual and craft cultures in present-day Bengal, which consists of Bangladesh and West Bengal, India. Maintaining the original Oitij-jo philosophy, the event will present a diverse range of disciplines including literature, visual arts, photography, film, music, performance, theatre \& dance, spoken word, architecture, design, fashion \& textiles and critical discourse. The inclusion of Bengal opens up the platform to those who identify with the rich Bengali cultural heritage before the India partition (1947). It taps into the creative industries of a regional Bengali heritage, a distinctive identity often overshadowed by a national Indian identity. This would also metaphorically open up artistic borders, break down cultural and artistic silos between West Bengal in India and Bangladesh and increase the reach for social capital amongst the Bengali creative community - all of which are key drivers of the collaborative economy approach (Stokes et al 2014). 
The launch event for 'AKHON: Where is Bengal Now' took place at the Rich Mix Centre (www.richmix.org), a community space in East London on the $24^{\text {th }}$ March 2016. The event was centred on performances from four female musicians of Bengali heritage (Gouri Chowdhury, 25-40; Sohni Alam 25-40; Sarah Sayeed 25-40; DJ DEBONAIR 21-25). The event introduced Oitij-jo to old and new audiences and the host for the night (female, age 2540, TV host) introduced the aim and objectives for Oitij-jo 2017/ 2018. The event attracted over 80 people and the inclusion of Bengal heritage was seen as a positive step forward. A West Bengali audience member (male, age 25-40) felt the mixture of audience ranging from young to old, Bangladeshi and Bengali, singers, local community members and those from outside of East London was a positive sight. However the challenge around receiving mainstream press coverage and widening audience reach and interest for financial investment still remain a barrier.

A diverse audience at 'Akhon: What is Bengal Now' reinforced some of the best practice ways of working from Oitij-jo's inaugural event in 2013. The diverse audience at the March 2016 launch event relied heavily on decentralised and informal digital word of mouth communication across Oitij-jo's personal social media platforms and Rich Mix's website and email database. These non-physical networks (volunteer social media accounts) generated by the event challenged the popular policy idea that centralised and physical networks are the only drivers to building a creative community (such as creative class, clustering and creative cities). One of the key drivers of access to the 2013 event for artists and audience was the informal networks created through the Internet. Therefore it was recognised that one of the ways to build on the success of Oitij-jo 2013 for Oitij-jo 2017/ 2018 is to capitalise on the decentralised network capabilities of the collaborative economy approach, for example utilising the capabilities of extending reach quickly through volunteer social media networks. However it was noted that future success is also dependent on a blended approach of utilising both technological and non-technological networks.

Although, technology allowed the project to grow at a rapid rate through various platforms at a low cost, some of the challenges of raising awareness around the event were not alleviated 
by accessible marketing tools like social media. The heavy dependence on social media meant networks were constrained to younger audiences, personal networks of those already engaged in the project and users of Facebook and Twitter. Skills sharing gained the most strength during the physical planning stage. However it was difficult to measure skills sharing via social media posts and it was difficult to engage the audience through tools such as Twitter, which only gained seventy followers. Furthermore, even though the strategic location choice of an East London community space for the 'Akhon: Where is Bengal Now' launch was based on the feedback to make the event physically accessible to the community, it proved challenging to get the desired audience numbers. Without links to formal centralised networks such as public funding, local council and government support, the advantages of the blended approach of securing a good geographic location (with good community reach) alongside digital co-location was difficult to realise. The launch event received little mainstream press and investment leads. The heavy reliance on unpaid skills meant it was difficult to maintain a post-event social media strategy required to build on and evaluate the impact of the event. It became difficult to gather the data required to put together mainstream funding applications that sought accountability. According to one of the organisers (male, 2540 age) interviewed, 'it is cost effective, it makes it easier to implement, but it also means because there is so much content out there now that tactics used need to be fresh and engaging, so the challenge will be to come up with strategies that inspire new audiences and promote the festival participants in the best possible light'.

To undertake these strategies further, ongoing volunteer support is required, and for this support to be sustainable in the long-term, funding is required. One volunteer working on the fashion design and textiles strand of Oitij-jo 2017/ 2018 explained over email, how she would like to take part in Oitij-jo events and sees it as an essential platform to promote the practice of artists, and for encouraging the Bangladeshi community in London to engage with the creative sectors. However she believes, given that artists are already struggling to receive paid work in London, 'without a small budget for materials it would prove difficult to take part' (Female, age 25-40, textile artist). Furthermore, feedback from several unsuccessful public funding applications for Akhon: Where is Bengal Now reinforced the lack of understanding of diversity and complexity of collaborative economy approaches by public 
funders. One funding body was unwilling to fund 'staff/volunteer costs' and to support several 'wider projects' (anonymous public funder, 2016) and another required centralised outputs linked to narrow outcomes which purported to alleviate 'poverty' in troubled economically deprived regions of the UK, or addressed the complex issues of 'religious radicalisation' (anonymous public funder, 2016). It became clear that creative industries, which are seen to reside outside of politically topical and popular policy arenas, are unlikely to receive support, financial or otherwise.

For Oitij-jo the success of future event relies on how volunteer skills and entrepreneurial exchanges are rewarded through continuous support and engagement, both digital and nondigital across generations with diverse political and social views. For this to be successful, large-scale funding is required. With arts funding being cut across the UK and particularly London (DCIM 2016), public funding remains a barrier to success. For instance, to register as a charity with the Charity Commission, it is now necessary to show at least $£ 5000$ in the bank of the organisation. Therefore fundraising needs to be sought and based on a portfolio approach.

One of the advantages of a collaborative economy approach is that it lends well to moving away from centralized fundraising approaches. Thus a collaborative funding approach is perceived to be a possible way forward where funding can be crowd-sourced online and offline with a portfolio of key sponsors. Successful examples of this are crowd-sourced projects as seen through the emergence of crowd-funding marketplaces like CrowdCube and Indigogo. Other non-western examples include Projeckt.co a crowd-funding start-up in Bangladesh. Projeckt.co builds on the culture of giving in Bangladesh to empower creative community artists and entrepreneurs in Bangladesh who struggle to raise finance through public routes (see http://projekt.co). With a crowd-funding approach there is also the opportunity for sponsors to co-create with the artists for unique collaborations and innovations to take place.

Crowdfunding is a feasible option for Oitij-jo to promote and streamline geographic collaboration with technology. Through a crowd-sourced platform, the Oitij-jo team plan to 
engage with physical art practices and digital methods of preparation for the $2017 / 2018$ festival to gain a wider physical and digital reach. Plans include an open call or commissioning process on the crowd-funding platform to develop work directly with artists/ designers/ performers; select practitioners and invite them to exhibit and perform at the event; organising physical residency for creative practitioners from Bangladesh to UK and UK to Bangladesh and taking the events outside of London to other parts of the UK. The collaborative approach would also be augmented by linking with platforms like the 'SASIAN Journey' set up recently by Asian Heritage Foundation (www.asianheritagefoundation.org) in association with the Self Employed Women's Association. The SASIAN Journey platform brings together representatives to explore creativity and design led innovations that better link geo-political regions. For SASIAN Journey, connecting with South Asian diaspora is a core area of focus, therefore an opportunity for Oitij-jo to collaborate. Collaboration opportunities create a way forward, however the barriers to public funding still remain. Creating high quality content, planning, managing platforms and introducing volunteers to collaborative practices require initial financial investments and skills interventions, to train and support the project managers on financial and non-financial processes of the project.

In conclusion a collaborative economy approach of disparate activities can come together, irrespective of normative visibility of technology, talent and ownership within a community. However collaborative economy approaches still fall outside of normative policy making debates and remain a challenge for policy makers (Stokes et al 2014), as the success of such projects are difficult to measure immediately. They do not lend well to immediate or 'Xerox' (Pratt 2009) policy transfer often required to attract public investment. What Oitij-jo's journey also reveals is that greater levels of documentation of Bangladeshi creative projects are required to help policymakers understand the grassroots collaborative economy approaches taking place in the community. To avoid repeating a Xerox policy approach, not only is it essential to understand best practices but also an understanding of the diverse challenges, so that this knowledge can be transferred to education and funding policies which seek to connect and situate the UK Bangladeshi community within the opportunities of the growing UK creative economy. 
It can be seen from the Oitij-jo project that the collaborative economy is an emergent process. For many of the artists and volunteers involved it was not a straightforward process, there were moments of satisfaction and frustration, moments of entrepreneurship driven by desperation and others moments driven by creativity. Volunteers made these reflections only after the event. Greater moments of satisfaction for volunteers came about after the event through individual and group collaborations between volunteers and artists. This can be seen within with projects like Intergalactic Desh (www.londonsartistquarter.org/content/jane-hdee/intergalactic-desh), Portraits of Baul (www.interfaces.fishislandlabs.com) and Birongona the Play (www.komola.co.uk) (highlighted within infographic three). Collaborations that happened after the inaugural festival in 2013 demonstrate the emergent nature of successful volunteer engagement. As one delivery team member said over email 'getting involved is simple but requires a lengthy process of continual engagement' (male, artist, age 25-40).

For managers, a successful engagement process not only includes the planning, managing and engaging artists and volunteers, but also the consistent strive to involve and engage public and private funders looking to support such projects. Thereby continual strategic leadership support is required for Bangladeshi creative industry managers to deliver and communicate creative projects across diverse generations and audiences, which are often complicated by the lack of visibility to centralised access to technology, talent and tolerance. With time and budget constraints, managers cannot always focus beyond the task at hand, therefore investment needs to go into digital and non-digital cross-cultural leadership training support for managers. This is essential for supporting creative industry managers and creative leaders in the community who are constantly striving to engage and include the Bangladeshi community within the growth of the UK creative economies with limited resources and access to skills.

Oitij-jo was and is a platform for nurturing collaborative learning. Many of the nonBangladeshi artists involved in the Oitij-jo project found it to be a platform to reflect on their 
own heritage, against others, and a way to learn and value similarities and differences. For these artists, prior informal networks built through community, education and art practices catalysed their cultural learning. However, this wasn't the case for emerging Bangladeshi creatives who had limited prior networks to the creative industries. Yet it can be said, that access to networks through platforms like Oitij-jo and advances in education made within the Bangladeshi community indicate potential growth and opportunity for network building through cross-cultural and collaborative learning. This opportunity calls for managers to push for policy, which takes into account continual investment in the understanding of collaborative approaches and tools (such as digital and non-digital channels) that can create networks for better social integration. Furthermore, what Oitij-jo highlights is that a collaborative and decentralised approach to learning is essential for the development of both the British Bangladeshi creative community and the future of the development of UK creative industries. As this approach does not only rely on ownership approaches but access to creative and cultural environments, it allows better scope for the British Bangladeshi community to participate and add to the diversity and innovation of the growing UK creative economy.

Acknowledgements: The authors would like to thank all those involved in the development and continual support of Oitij-jo from its inception to where it is now. Particular thanks goes to Nòemi Zajzon for compiling the infographics. Nòemi first started with Oitij-jo in 2013 and her support for it continues. Nòemi Zajzon is a researcher and designer living in London. Her practice is based around curatorial, exhibition production and graphic design work and driven by an interest in creative engagement and socio-anthropological implications of spatial design. She trained to design spaces that challenge the way stories are told in the public realm, including exhibitions, community-centred projects and city narratives. She contributed to the development of Oitij-jo 2013 and supported the team with visual aids, like the infographics in the publication. zajzonnoemi@gmail.com 


\section{References}

Alzubaidi, Haider., Carr, Jane., Councell, Rachel, and Johnson, G. Households Below Average Income An Analysis of the Income Distribution 1994/95 - 2011/12. Department of Trade and Pensions UK. June 2013. Web 01 September 2015

$<$ https://www.gov.uk/government/uploads/system/uploads/attachment_data/file/206778/full_hbai13.p df $>$

Botsman, Rachel, and Rogers, Roo. What's Mine Is Yours: How Collaborative Consumption is Changing the Way We Live. 2010. New York: Harper Collins.

DCMS. UK Creative Industries Economic Estimates. January 2016. Web 01 September 2015

$<\mathrm{http}$ ://www.thecreativeindustries.co.uk/media/252528/ukti_creative_industries_action_plan_aw_rev _3-0_spreads.pdf >

DCMS. UK Creative Industries International Strategies. January 2014. Web 01 September 2015 $<$ http://www.thecreativeindustries.co.uk/media/252528/ukti_creative_industries_action_plan_aw_rev _3-0_spreads.pdf $>$

De Propris, Lisa, and Hypponen, Laura. Creative Clusters and Governance: The Dominance of the Hollywood Film Cluster. 2008. Cited In: Cooke, Philip, and Lazzeretti, Luciana, eds. Creative Cities, Cultural Clusters and Local Development, Cheltenham: Edward Elgar, pp. 340-371.

Evans, Graeme. Creative Cities, Creative Spaces and Urban Policy. 2009. Urban Studies. 46(5\&6) 1003-1040.

Florida, L. Richard. The Rise of the Creative Class: And How Its Transforming Work, Leisure, Community and Everyday Life. (2002). New York: Basic Books.

Kozinets, V. Robert. Netnography Redefined. (2015) $2^{\text {nd }}$ Edition. Sage: London

Landry, Charles. The Creative City: A Toolkit for Urban Innovators. 2000. Routledge

Li,Yaojun. Economist. Breaking Out. 21st Feb 2015. Web 01 September 2015

$<$ http://www.economist.com/news/britain/21644155-britain-bangladeshis-have-overtaken-pakistaniscredit-poor-job-market-when-they-arrived $>$

Lymperopoulou, Kitty. Still Disadvantaged? The Educational Attainment of Ethnic Minority Groups. Filed Under: Ethnicity. Manchester Policy Blogs. Manchester University. May 14, 2015. Web 01 September $2015<\mathrm{http} / / /$ log.policy.manchester.ac.uk/featured/2015/05/still-disadvantaged-theeducational-attainment-of-ethnic-minority-groups/>

Mommaas, Hans. Spaces of Culture and Economy: Mapping the Cultural-Creative Cluster Landscape. 2009. Cited in Kong, Lily, and O’Connor, Justin, eds. Creative Economies, Creative Cities: AsianEuropean Perspectives. 2009. Springer.

Nichols-Clarke, Terry, ed. The City as Entertainment Machine. 2004. Oxford: Elsevier. 
O'Connor, Justin, and Kong, Lily. Introduction. Chapter One. 2009. Cited in Kong, Lily, and O'Connor, Justin, eds. Creative Economies, Creative Cities: Asian-European Perspectives. 2009. Heidelberg, Germany Springer.

Oitij-jo (2015). Business Plan 2015-2017. September 2015. Unpublished

Oitij-jo (2013). Website. Web 01 September $2015<$ www.oitijjo.org>

ONS. Ethnicity \& Labour Market, 2011 Census for England \& Wales

Poverty: Low income \& ethnicity. 13 Nov 2014. Web 01 September $2015<$ http://www.poverty.org.uk/06/index.shtml>

Porter, Micheal. The Competitive Advantage of Nations, Harvard Business Review. (1990) MarchApril Issue. Web $24^{\text {th }}$ August $2015<$ https://hbr.org/1990/03/the-competitive-advantage-of-nations>

Pratt, C. Andy. Policy Transfer and the Field of the Cultural and Creative Industries: Learning from Europe? Creative Economies, Creative Cities: Asian European Perspectives (2009). Cited in Kong, Lily, and O'Connor, Justin, eds. Creative Economies, Creative Cities: Asian-European Perspectives. 2009. Heidelberg, Germany Springer.

Pratt, C. Andy. Creative Clusters: Towards the Governence of the Creative Industry Production System?. Media International Australia. (2004). 112: 50-66.

Radjou, Navi., Prabhu, Jaideep, and Ahuja, Simone. Jugaad Innovation: Think Frugal, Be Flexible, Generate Breakthrough Growth. (2012). John Wiley and Sons.

Saxena, B. Sanchita. Made in Bangladesh, Cambodia and Sri Lanka: The Labor Behind the Global Garments and Textiles Industries. (2014). USA: Cambria Press.

Somerville,Will., Sriskandarajah, Dhananjayan, and Latorre, Maria. A Reluctant Country of Immigration. $21^{\text {st }}$ July 2009. Migration Policy Institute, Migration Information Source, UK.

Stokes, Kathleen., Clarence, Emma., Anderson, Lauren, and Rinne, April. Making Sense of the UK Collaborative Economy. 2014. Nesta UK Collaborative Lab.

Visram, Rozina. Asians in Britain. 2002. London \& Sterling.

Visram, Rozina. Ayahs, Lascars and Princes: Indians in Britain: 1700-1947. 1986. Pluto Press: Virginia

Figure 1: Infographic 1: The Story of Oitij-jo 2013, created by Nòemi Zajzon® $\odot$

Figure 2: Infographic 2: Digital and Non-digital Skills Sharing Map, created by Nòemi Zajzon(C) Figure 3: Infographic 3: A Timeline of Collaborations, created by Nòemi Zajzon(C)

Figure 4: Infographic 4: Networks, created by Nòemi Zajzon $(\mathbb{C}$ 